\section{Case Reports in Ophthalmology}

\title{
Endophthalmitis following 27-Gauge Pars Plana Vitrectomy for Vitreous Floaters
}

\author{
Zhong Lin ${ }^{a} \quad$ Rong Han Wu ${ }^{a}$ Nived Moonasar ${ }^{b}$ \\ ${ }^{a}$ The Eye Hospital, School of Ophthalmology and Optometry, Wenzhou Medical \\ University, Wenzhou, China; ${ }^{b}$ Ophthalmology Department, University of the West Indies, \\ St. Augustine, Trinidad and Tobago
}

\section{Keywords}

Endophthalmitis $\cdot 27$-gauge pars plana vitrectomy $\cdot$ Vitreous floaters

\begin{abstract}
Purpose: To report a case of Staphylococcus epidermidis endophthalmitis following 27-gauge pars plana vitrectomy for symptomatic vitreous floaters. Methods: The clinical course and imaging findings, including fundus optomap, and spectral domain optical coherence tomography of a 24-year-old male patient were documented. Results: The patient, with a preoperative best-corrected visual acuity (BCVA) of 1.0, developed endophthalmitis following 27-gauge pars plana vitrectomy for symptomatic vitreous floaters. After a series of treatments, including emergent vitreous tap and silicone oil injection, antibiotic treatment, and silicone oil removal, the patient regained a BCVA of 0.6. Conclusion: Although rare, the potential risk of endophthalmitis should be explicitly discussed with patients considering surgical intervention for vitreous floaters.

(C) 2016 The Author(s) Published by S. Karger AG, Basel
\end{abstract}

\section{Introduction}

The incidence of endophthalmitis after 20-gauge, 23-gauge, and 25-gauge pars plana vitrectomy (PPV) was recently reported to be $1 / 4,403(0.02 \%), 1 / 3,362(0.03 \%)$, and $1 / 789$ $(0.13 \%)$, respectively [1]. Although rare, endophthalmitis is a vision-threatening complica- 


\section{Case Reports in Ophthalmology}

Case Rep Ophthalmol 2016;7:245-250

DOI: $10.1159 / 000452733$

c 2016 The Author(s). Published by S. Karger AG, Basel www.karger.com/cop

Lin et al.: Endophthalmitis following 27-Gauge Pars Plana Vitrectomy for Vitreous Floaters

tion following PPV. A multicenter, retrospective, interventional study reported the postoperative complications of 27-gauge PPV, including transient ocular hypertension (8.4\%), transient hypotony (5.3\%), and vitreous hemorrhage (5.3\%) [2]. However, no case of postoperative endophthalmitis was encountered [2]. To the best of our knowledge, the incidence of endophthalmitis after 27-gauge PPV has not been reported. A case of Staphylococcus epidermidis endophthalmitis which subsequently developed following 27-gauge PPV for symptomatic vitreous floaters in a healthy young male is hereby reported. The case followed the tenets of the Declaration of Helsinki and was approved by the Ethics Committee of the Eye Hospital of Wenzhou Medical University.

\section{Case Report}

A healthy 24-year-old male complained of a 7-year history of an apparent floater after a basketball bump to the left eye, which interfered with his daily life. Neodymium-doped yttrium aluminum garnet (Nd:YAG) vitreolysis was performed a year before the admission; however, the procedure did not result in his satisfaction. The admission uncorrected visual acuity (UCVA) and best-corrected visual acuity (BCVA) were 0.3 and 1.0 in both eyes, respectively. Spherical equivalent and axial length were around $-5 \mathrm{dpt}$ and $26 \mathrm{~mm}$, respectively, in both eyes. Examination was normal except for a prominent posterior vitreous detachment and vitreous opacity in the left eye (OS). Observation was advised, but the patient strongly requested treatment. After obtaining informed consent, a 27-gauge sutureless 3-port PPV was performed without intraoperative complications. Tobradex OS q2h and tropicamide OS qn were administered postoperatively.

On the morning of postoperative day 1, UCVA OS was 0.12 ; intraocular pressure (IOP) was $10 \mathrm{~mm} \mathrm{Hg}$. Anterior segment examination revealed no eyelid edema, mild conjunctival injection, and 1+ aqueous cell with no posterior synechiae, hypopyon, or fibrin. Fundus examination showed a clear vitreous chamber and a smooth fundus. Upon nightfall, the patient complained of mild pain in the left eye. However, the slit lamp and indirect 90D ophthalmoscope examination was similar as that in the morning. On the morning of postoperative day 2 , the patient complained of severe pain and blurred vision in the left eye. The UCVA sharply decreased to counting fingers, while the IOP was still normal $(10 \mathrm{~mm} \mathrm{Hg})$. The slit lamp examination showed mixed conjunctival injection, massive fibrin in the anterior chamber and vitreous chamber, and a blurred fundus (Fig. 1a, b). The patient was diagnosed with endophthalmitis and underwent emergent vitreous tap, injection with intravitreal vancomycin $(1 \mathrm{mg} / 0.1 \mathrm{~mL})$, ceftazidime $(2.25 \mathrm{mg} / 0.1 \mathrm{~mL})$, triamcinolone $(0.2 \mathrm{mg})$, and silicone oil injection. During the operation, we observed optic disc congestion and swelling, retinal exudation and hemorrhage, peripheral retinal necrosis, vessel occlusion, and macular edema (Fig. 1c). Vitreous culture revealed gram-positive cocci. Hence, intravenous meropenem $500 \mathrm{mg} \mathrm{q} 8 \mathrm{~h}$, dexamethasone $5 \mathrm{mg}$ bid, and topical levofloxacin OS q2h, prednisolone OS q2h and tropicamide OS qid were administered postoperatively.

The eye responded well to the treatment. At day 9 after operation, the UCVA and BCVA improved to 0.12 and 0.2 , respectively. The fibrin of the anterior chamber was greatly reduced, and the panoramic ophthalmoscope (Daytona, P200T) revealed a visible retina (Fig. 2a). Spectral domain optical coherence tomography (Heidelberg, TR-KT-2841, Germany) revealed an irregular retinal surface with a silicone oil interface (Fig. 2b). Vitreous cultures isolated S. epidermidis, which was susceptible to levofloxacin, vancomycin, gentamicin, and ceftazidime. Intravenous medicine was subsequently stopped, and oral prednisone $30 \mathrm{mg} \mathrm{qd}$ 
Case Reports in
Ophthalmology

Case Rep Ophthalmol 2016;7:245-250

DOI: $10.1159 / 000452733$

C 2016 The Author(s). Published by S. Karger AG, Basel www.karger.com/cop

Lin et al.: Endophthalmitis following 27-Gauge Pars Plana Vitrectomy for Vitreous Floaters

(with a weekly tapered dose), was administered. By postoperative month 2, both UCVA and BCVA improved to 0.3. After silicone oil removal, the BCVA improved to 0.4. Fundus examination revealed a clear vitreous cavity and retina (Fig. 3a). Spectral domain optical coherence tomography revealed an irregular retinal surface but an intact ellipsoid layer (Fig. 3b). At month 5 after operation, the BCVA improved to 0.6.

\section{Discussion}

Recent studies found that floaters are perceived by patients as a serious medical condition that has a significant negative impact on their vision and quality of life $[3,4]$. In a study by Webb et al. [4] with participants aged 30 years on average, $76 \%$ reported symptomatic floaters and 33\% reported noticeable impairment in vision from floaters. A utility analysis reported that patients with symptomatic floaters were willing to risk a 7\% chance of blindness and $11 \%$ risk of death to rid themselves off the symptoms [5]. Clearly, a large proportion of patients are motivated to remove their floaters. At present, small-gauge vitrectomy seems to be the only effective therapy for symptomatic floaters. However, though rare, this invasive treatment does have some complications, e.g., the postoperative cataracts (frequency ranging from 22.5 to $60 \%$ ) [6-8], iatrogenic retinal break (frequency ranging from 0 to $16.4 \%$ ) $[8,9]$, and even endophthalmitis (3 cases reported) $[10,11]$.

In 2 prospective, nationwide studies investigating the endophthalmitis developed after PPV in the UK, Park et al. [10], reported 2 cases of endophthalmitis following 23-gauge PPV for vitreous opacities, both of which were caused by gram-positive cocci (one was $S$. epidermidis). One patient regained a visual acuity of $6 / 9$ at 6 months; however, the other patient developed persistent cystoid macular edema and only recovered 6/96 vision [10]. Recently, Henry et al. [11] reported a case of Staphylococcus caprae endophthalmitis in a young healthy female after 20-gauge 3-port vitrectomy for floaters. The female underwent an emergent vitreous tap and injection with intravitreal vancomycin, ceftazidime, and dexamethasone. At month 9 postoperatively, the female regained a BCVA of 20/80 [11]. To the best of our knowledge, this is the first reported case of endophthalmitis which followed a 27gauge vitrectomy for floaters. This case of endophthalmitis was also caused by Grampositive cocci (S. epidermidis), and the patient regained a BCVA of 0.6 (or 30/50) at the last follow-up.

\section{Conclusions}

More healthy young people with excellent vision are eager to resolve their floaters. Although rare, endophthalmitis is a potentially devastating complication for patients undergoing a seemingly straightforward PPV for vitreous floaters. This severe risk as well as other risks, such as transient hypotony, retinal tear, and long-term complicated cataract, should be explicitly addressed, and consent should be obtained from patients who are considering this treatment modality.

\section{Statement of Ethics}

The authors have no ethical conflicts to disclose. 


\section{Case Reports in Ophthalmology}

\section{Disclosure Statement}

The authors declare that they have no conflicts of interest.

\section{References}

1 Scott IU, Flynn HW Jr, Acar N, et al: Incidence of endophthalmitis after 20-gauge versus 23-gauge versus 25-gauge pars plana vitrectomy. Graefes Arch Clin Exp Ophthalmol 2011;249:377-380.

2 Khan MA, Shahlaee A, Toussaint B, et al: Outcomes of 27 gauge microincision vitrectomy surgery for posterior segment disease. Am J Ophthalmol 2016;161:36-43 e32.

- Zou H, Liu H, Xu X, Zhang X: The impact of persistent visually disabling vitreous floaters on health status utility values. Qual Life Res 2013;22:1507-1514.

-4 Webb BF, Webb JR, Schroeder MC, North CS: Prevalence of vitreous floaters in a community sample of smartphone users. Int J Ophthalmol 2013;6:402-405.

-5 Wagle AM, Lim WY, Yap TP, Neelam K, Au Eong KG: Utility values associated with vitreous floaters. Am J Ophthalmol 2011;152:60-65 e61.

-6 Schulz-Key S, Carlsson JO, Crafoord S: Longterm follow-up of pars plana vitrectomy for vitreous floaters: complications, outcomes and patient satisfaction. Acta Ophthalmol 2011;89:159-165.

7 Mason JO 3rd, Neimkin MG, Mason JO 4th, et al: Safety, efficacy, and quality of life following sutureless vitrectomy for symptomatic vitreous floaters. Retina 2014;34:1055-1061.

8 Sebag J, Yee KM, Wa CA, Huang LC, Sadun AA: Vitrectomy for floaters: prospective efficacy analyses and retrospective safety profile. Retina 2014;34:1062-1068.

-9 Tan HS, Mura M, Lesnik Oberstein SY, Bijl HM: Safety of vitrectomy for floaters. Am J Ophthalmol 2011;151:995-998.

10 Park JC, Ramasamy B, Shaw S, Ling RH, Prasad S: A prospective and nationwide study investigating endophthalmitis following pars plana vitrectomy: clinical presentation, microbiology, management and outcome. Br J Ophthalmol 2014;98:1080-1086.

11 Henry CR, Smiddy WE, Flynn HW Jr: Pars plana vitrectomy for vitreous floaters: is there such a thing as minimally invasive vitreoretinal surgery? Retina 2014;34:1043-1045.
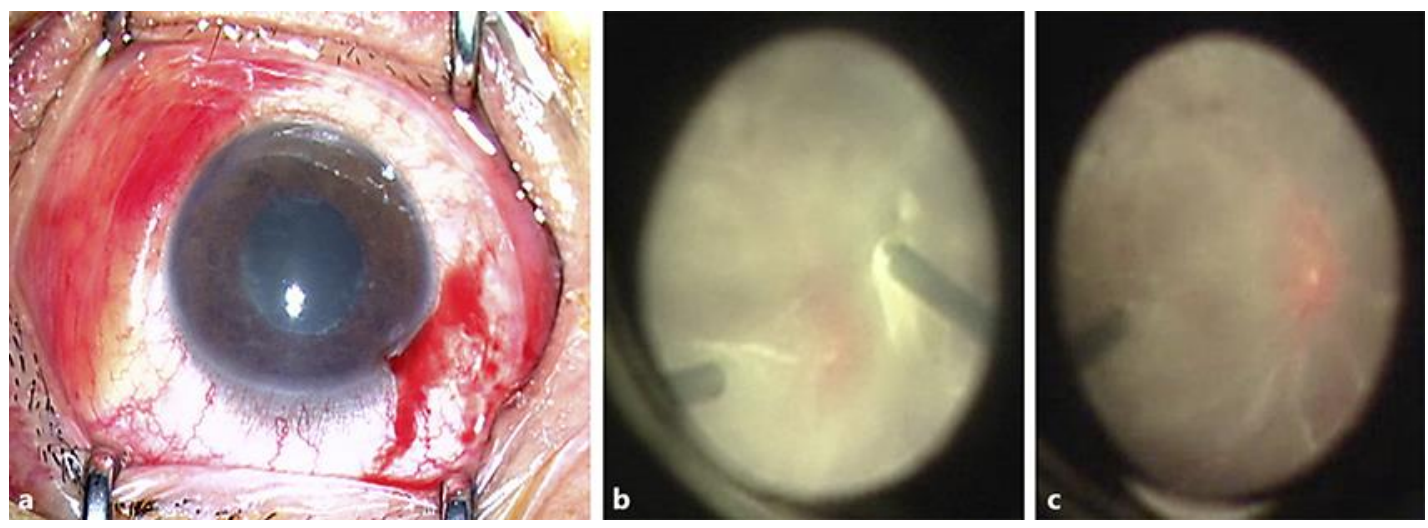

Fig. 1. The appearance of anterior segment and fundus during surgery. a Anterior segment appearance at the beginning of surgery. $\mathbf{b}$ Fundus posterior pole image at the beginning of surgery showed massive fibrin in the vitreous chamber and a blurred fundus. c Fundus posterior pole image at the end of surgery showed optic disc congestion and swelling, retina exudation and hemorrhage, peripheral retina necrosis, vessel occlusion, and macular edema. 
Case Reports in
Ophthalmology

Case Rep Ophthalmol 2016;7:245-250

DOI: $10.1159 / 000452733$

(c) 2016 The Author(s). Published by S. Karger AG, Basel www.karger.com/cop

Lin et al.: Endophthalmitis following 27-Gauge Pars Plana Vitrectomy for Vitreous Floaters
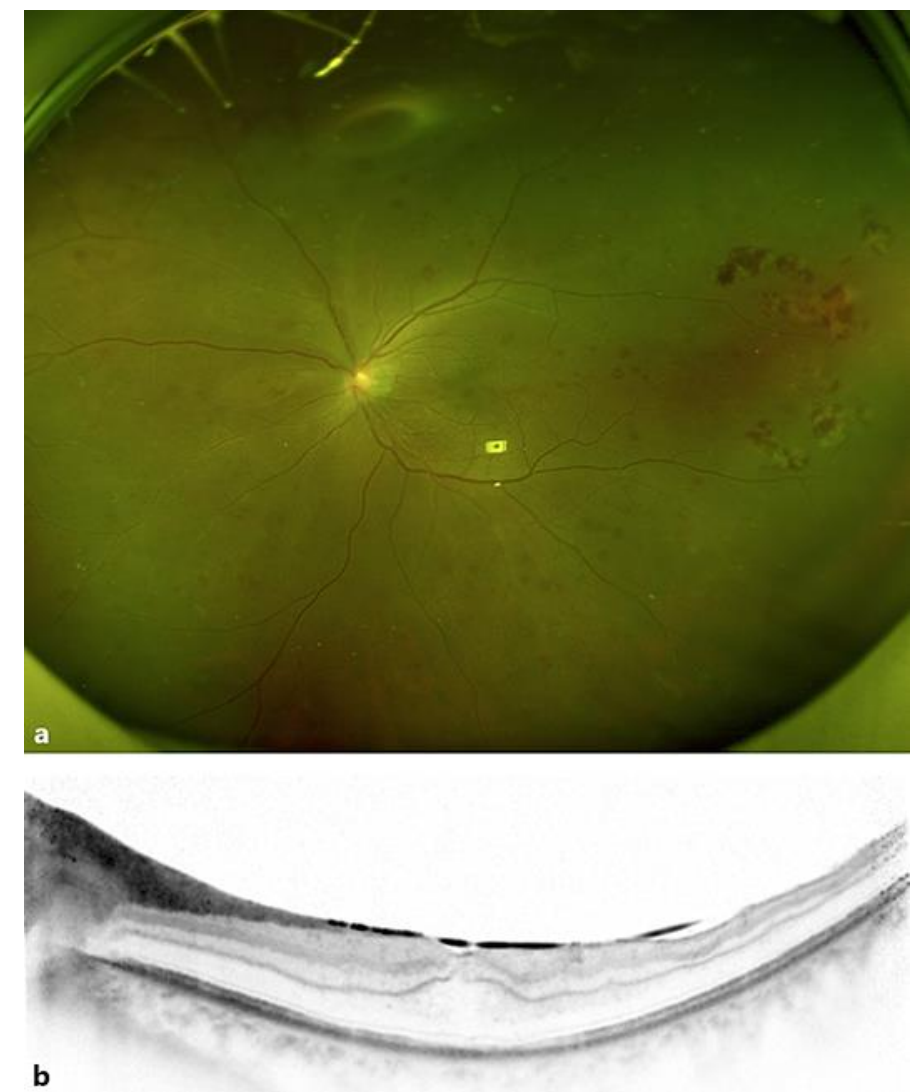

Fig. 2. Postoperative day 9 appearance. a Panoramic ophthalmoscope showed an apparently improved fundus. b Spectral domain optical coherence tomography revealed an irregular retinal surface with a silicone oil interface. 
Case Reports in
Ophthalmology

Case Rep Ophthalmol 2016;7:245-250

(c) 2016 The Author(s). Published by S. Karger AG, Basel www.karger.com/cop

Lin et al.: Endophthalmitis following 27-Gauge Pars Plana Vitrectomy for Vitreous Floaters
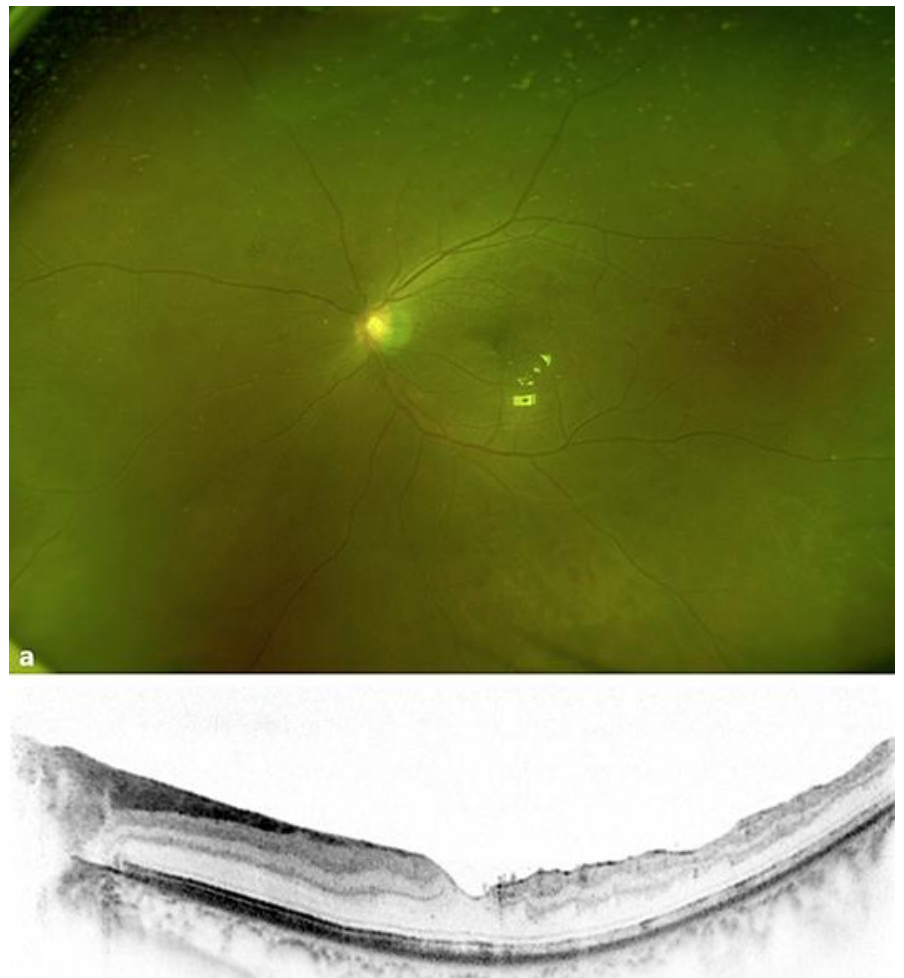

b

Fig. 3. Postoperative month 2 (after silicone oil removal) appearance. a Panoramic ophthalmoscopy showed a clear vitreous cavity and retina. b Spectral domain optical coherence tomography revealed an irregular retinal surface but an intact ellipsoid layer. 